\title{
A contribuição da Licenciatura em Educação do Campo UFCG para a formação docente e a prática pedagógica das escolas no Cariri paraibano: concepção dos egressos
}

Maria do Socorro Silva ${ }^{1}$, Moizés de Souza Alves ${ }^{2}$

1, 2 Universidade Federal de Campina Grande - UFCG. Unidade Acadêmica de Educação do Campo e Programa de PósGraduação em Educação. Rua Luiz Grande, S/N. Campus Universitário, Bairro Frei Damião. Sumé - PB. Brasil.

Autor para correspondência/Author for correspondence: maria.socorro@professor.ufcg.edu.br

RESUMO'. O presente texto é resultado de uma pesquisa vinculada ao Programa Institucional de Bolsa de Iniciação Cientifica (Pibic), cujo objeto foi a concepção dos egressos da Licenciatura em Educação do Campo-UFCG/CDSA e sua contribuição para a formação docente e prática pedagógica. A abordagem qualitativa, na perspectiva crítica (Gil, 2008; Gamboa, 1995), orientou todos os procedimentos realizados. Os sujeitos foram os egressos do curso, com foco nos que estão no exercício profissional. A análise documental e o questionário semiestruturado foram procedimentos metodológicos fundamentais para a produção dos dados, que foram organizados e analisados na perspectiva da análise temática (Bardin, 2010). Os resultados evidenciaram que: 116 dos egressos são do cariri paraibano; existe uma inserção dos egressos na docência em diferentes etapas, como na gestão escolar e práticas educativas não escolares; reconhecem a contribuição da Licenciatura para sua formação inicial e continuada, para inserção do debate sobre Educação do Campo nas redes do território. Os desafios foram à luta pela abertura de concursos públicos na região e no estado; pela manutenção das escolas nas comunidades e ampliação da oferta do ensino médio; a vivência da docência por área de conhecimento e a necessidade de um maior aprofundamento sobre a alternância no curso.

Palavras-chave: egressos, licenciatura em educação do campo, formação docente, pibic, prática pedagógica. 


\title{
The contribution of Licensing in Rural Education from UFCG for teaching and pedagogical practice of in Cariri region schools in Paraiba state: egresses concepts
}

\begin{abstract}
This text is the result of a research linked to the institutional scientific initiation scholarship program (pibic), whose object was the conception of the graduates from Rural Education course-UFCG/CDSA and their contribution to teacher training and pedagogical practice the qualitative approach, in a critical perspective (Gil, 2008; Gamboa, 1995), guided all the procedures performed. The subjects were the graduates of the course, focusing on those who are in professional practice. The document analysis and the semi-structured questionnaire were fundamental methodological procedures for the production of data, which were organized and analyzed from the perspective of thematic analysis (Bardin, 2010). The results showed that: 116 of the graduates are from the Cariri region of Paraíba state; there is an insertion of graduates in teaching at different stages, such as in school management and non-school educational practices; recognize the licentiate's contribution to their initial and continuing education, to insert the debate on rural education in the territory networks the challenges were the struggle to open public purposes in the region and in the state; for the maintenance of schools in the communities and expansion of the supply of secondary education; the experience of teaching by area of knowledge and the need for a deeper understanding of the alternation in the course.
\end{abstract}

Keywords: graduates, degree in rural education, teacher training, pibic, pedagogical practice. 


\section{La contribución del Grado en Educación en el Campo UFCG a la formación de maestros y la práctica pedagógica de las escuelas del Cariri paraibano: concepción de egresados}

RESUMEN. Este texto es el resultado de una investigación ligada al Programa Institucional de Bolsa de Iniciação Científica (Pibic), cuyo objeto fue la concepción de los egresados de la licenciatura en Educação do Campo-UFCG/CDSA y su aporte a la formación docente y práctica pedagógica. El abordaje cualitativo, en perspectiva crítica (Gil, 2008; Gamboa, 1995), guió todos los procedimientos realizados. Los sujetos fueron los egresados del curso, centrándose en los que se encuentran en actividad profesional. El análisis de documentos y el cuestionario semiestructurado fueron procedimientos metodológicos fundamentales para la producción de datos, los cuales fueron organizados y analizados desde la perspectiva del análisis temático (Bardin, 2010). Los resultados mostraron que: 116 de los graduados son de la región Cariri de Paraíba; hay una inserción de los egresados en la docencia en diferentes etapas, como en la gestión escolar y las prácticas educativas extraescolares; Reconocer la contribución del Licendiado a su formación inicial y continua, para insertar el debate sobre la Educación Rural en las redes del territorio. Los desafíos fueron la lucha por abrir exames para cargos públicos en la región y en el estado; para el mantenimiento de escuelas en las comunidades y ampliación de la oferta de educación secundaria; la experiencia de la docencia por áreas de conocimiento y la necesidad de una comprensión más profunda de la alternancia en el curso.

Palabras clave: graduados, licenciada en educación rural, formación docente, pibic, práctica pedagógica. 


\section{Introdução}

Pois é.

A gente vive aqui e de repente descobre que aqui pode ser outro lugar.

Um lugar desconhecido,

Ou nunca visto

Ou nunca notado.

Luís Fernando Veríssimo

Este texto é resultado da pesquisa:

A Contribuição da Licenciatura em

Educação do Campo UFCG para a formação docente e a prática pedagógica das escolas no cariri paraibano, vinculada ao Núcleo de Estudos e Pesquisa em Educação do Campo, Formação de Professores/as e Prática Pedagógica (Nupeforp), e contou com o apoio do Projeto Interinstitucional de Bolsas de Iniciação à Docência- Pibic/Capes/UFCG.

Os vínculos sociais de origem da Educação do Campo, a partir de uma política de educação da classe trabalhadora do campo ${ }^{\mathrm{ii}}$, centraram-se na tríade campopolítica pública-educação. A discussão por um projeto de campo que tem como protagonista a classe trabalhadora do campo, a forma de produzir e reproduzir a vida, por isto,

Utilizar-se-á a expressão campo, e não a mais usual, meio rural, com o objetivo de incluir no processo da conferência uma reflexão sobre o sentido atual do trabalho camponês $e$ das lutas sociais e culturais dos grupos que hoje tentam garantir a sobrevivência desse trabalho. Mas, quando se discutir a educação do campo, se estará tratando da educação que se volta ao conjunto dos trabalhadores e das trabalhadoras do campo, sejam os camponeses, incluindo os quilombolas, sejam as nações indígenas, sejam os diversos tipos de assalariados vinculados à vida e ao trabalho no meio rural. Embora com essa preocupação mais ampla, há uma preocupação especial com o resgate do conceito de camponês. Um conceito histórico e político... (Kolling, Nery \& Molina, 1999, p. 26).

A Educação do Campo tem na sua materialidade de origem a necessidade de superação de um modelo de desenvolvimento gerador de assimetrias sociais, políticas e econômicas, e de um campo sem gente. A concepção de Educação tem na sua tessitura um território com gente, que produz suas existências, culturas, saberes e afetos, numa ruralidade caracterizada pela agricultura familiar/camponesa, numa perspectiva da sustentabilidade da vida, do ambiente e das comunidades (Silva, 2009). Portanto, tem como ponto de partida um projeto contra hegemônico de Campo, que se fundamenta na Agricultura Familiar/Camponesa, na Reforma Agrária, na Agroecologia e na Convivência com o Semiárido (Caldart, 2009; Michelotti.2014; Molina \& Hage, 2015; Silva, 2009).

Isso coloca a institucionalidade da Licenciatura em Educação do Campo, num 
território de contradições que não tem apenas dimensão administrativas, pedagógicas e financeiras, mas a luta de classes, a revalorização do trabalho do camponês, pode ser para a emancipação humana e a recriação e resistência dos sujeitos do campo por meio dos seus saberes. Essas foram premissas fundamentais para a formulação e institucionalização da Licenciatura em Educação do Campo, em 2009, no Centro de Desenvolvimento Sustentável do Semiárido da Universidade Federal de Campina Grande (UFCG).

O processo de expansão da UFCG (sempre foi multicampi desde a UFPB ${ }^{\mathrm{iii}}$ ) se fortaleceu com a política de interiorização do ensino superior do governo federal, a partir de 2005. Neste cenário, emerge com o processo de mobilização das organizações sociais e do poder público do território do Cariri Paraibano, que se materializou com o "Grito do Cariri", a criação do Centro de Desenvolvimento Sustentável do Semiárido - CDSA, tendo como um dos seus cursos estruturadores a Licenciatura em Educação do Campo LeCampo.

O Curso de Licenciatura em Educação do Campo - LeCampo, é uma modalidade de graduação em licenciatura que objetiva formar e habilitar profissionais para atuação nos anos finais do Ensino Fundamental e Ensino Médio, por área de conhecimento, e também para gestão dos processos educativos escolares e dos processos educativos comunitários e se constitui, no Brasil, a partir da luta dos movimentos sociais do campo pelo direito a educação básica e superior contextualizada a sua realidade, num território de contradições que não tem apenas dimensões administrativas, pedagógicas e financeiras, mas também a luta de classes, a revalorização do trabalho camponês, para a emancipação humana e a recriação e resistência dos Povos do Campo, das Florestas e das Águas.

A Lecampo, a partir de 2013 já começou a formar oslas primeiroslas Licenciados \as em Educação do Campo, o que nos leva, após este tempo, a sentir a necessidade de registrar e avaliar este itinerário, bem como identificar as contribuições trazidas por este curso para a formação docente e a prática pedagógica no território do Cariri Paraibano.

A escolha do Cariri como lócus para implantação do curso deve-se a vários fatores, dentre os quais destacamos:

Contexto econômicopolítico-social permeado pela agricultura e pecuária familiar, em contradição com o alto índice de concentração de terra;

O surgimento dos assentamentos rurais no território, a partir 
da década de 1990, o que possibilitou a presença de novos movimentos sociais na região, dentre estes a Comissão Pastoral da Terra-CPT e o Movimento dos Trabalhadores Rurais Sem Terra - MST;

Contexto educacional de exclusão de ensino médio e superior de parcela significativa da população na faixa etária correspondente, especialmente os que residiam na denominada área rural do território;

Ação extensionista da UFCG, no território, por meio do Projeto Unicampo $^{\text {iv }}$, que realizava um trabalho de formação com lideranças de assentamentos e das comunidades rurais;

Organização do Fórum Territorial de Desenvolvimento Rural Sustentável, que colocou na pauta do território o debate sobre as políticas públicas e a gestão social, constituindo uma Comissão de Educação do Campo no território;

A presença de organizações sociais populares que passaram a trabalhar com o paradigma da convivência com o Semiárido, trazendo para a pauta política do território do Cariri o debate sobre Agroecologia, Educação do Campo e Tecnologias Sociais de Convivência com o
Semiárido, dentre as quais destacamos: $\mathrm{O}$ Projeto Dom Hélder Câmara, o Serviço de Tecnologia Alternativa - Serta;

A existência no espaço, onde hoje se localiza o CDSA da Escola Agrícola de Sumé, que ofertava anos finais do ensino fundamental para adolescentes das comunidades rurais, com formação técnica voltada para a convivência com o semiárido.

Tais fatores envolveram diferentes sujeitos coletivos que pautaram a luta pela implantação do Campus, especificamente no município de Sumé, por ser na área central do território, e muito próximo ao Sertão do Pajeú-Pernambucano, o que ampliaria o atendimento à demanda da região. A interiorização de um Campus da UFCG foi de suma importância para assegurar o direito dos sujeitos sociais nestes territórios de acessarem a Universidade. Vejamos a localização do Cariri Paraibano no Brasil e no Estado da Paraíba: 
Mapa 1 - Municípios do Cariri Ocidental Paraibano e sua localização no Brasil e na Paraíba.

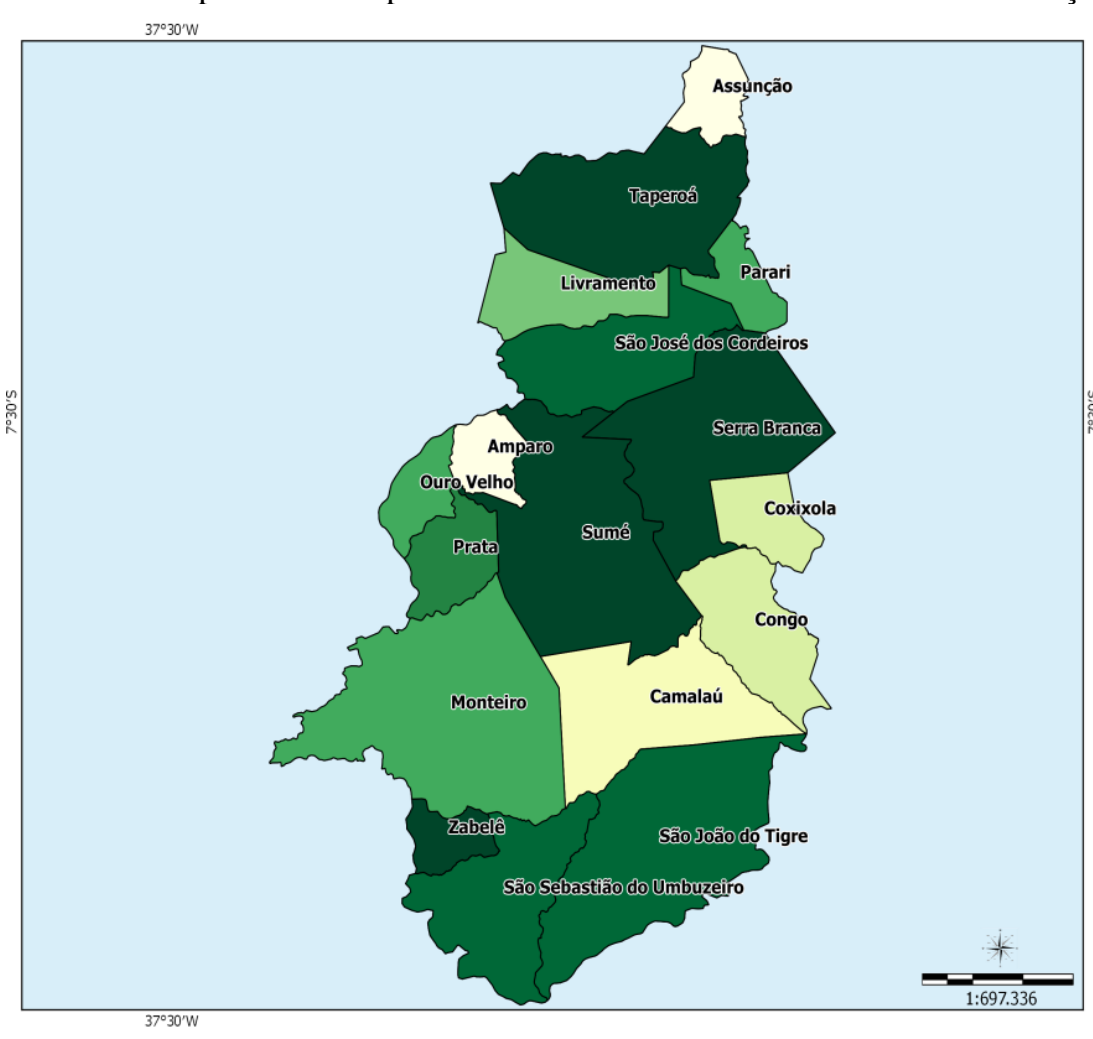

Fonte: IBGE, 2006

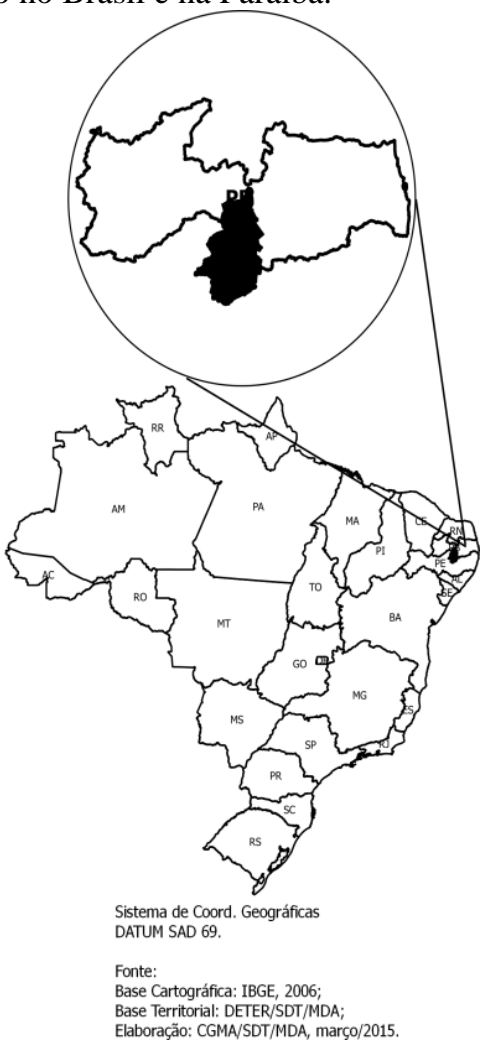

Outra questão importante para a organização da oferta da Licenciatura na UFCG foi a configuração territorial do Cariri Paraibano como, por exemplo, a distância do município de Sumé dos outros 17 (dezessete) municípios do território, a integração com rodovias da maioria deles e a marca de ruralidade muito forte nestes municípios, o que contribuiu para se pensar a Alternância pedagógica com uma presença mais permanente na Universidade, articulada com tempo comunidade mais curtos e formas diversas de acompanhamento e monitoramento dos estudantes.

O concurso público para docência na Licenciatura possibilitou uma diversidade neste perfil de militância junto aos movimentos camponeses e sindical, tempo de exercício profissional, conhecimento da realidade e prática das escolas no campo, o que já se constituiu como um desafio no seu itinerário e na formação dos egressos/as do curso, assim,

como as diferenças intracampo nos mostraram a diversidade das territorialidades e dos sujeitos camponeses, o mesmo se dá com a implementação da alternância nas Universidades em todo Brasil. Essas marcas acabam gerando um desenho bastante diverso nas licenciaturas em todo país, o que representa também uma nova forma de pensar e materializar a política educacional, rompendo com seu caráter historicamente homogeneizador. (Silva, 2019, p. 235). 
Tal contexto coloca desafios para a Universidade enquanto espaço de pesquisa e produção do conhecimento e, consequentemente, como formadora de profissionais e educadores (as) que possam contribuir para a construção de referenciais e práticas de sustentabilidade para a região.

No levantamento realizado com os \as egressos $\backslash a s$ identificamos que $46 \%$ tinham concluído o ensino médio entre 1996 e 2000. Portanto, já estava há mais de 09 anos sem ter acesso ao ensino superior, pela dificuldade de se deslocar para o município de Campina Grande (município de médio porte com campus da UFCG e UEPB, distante 135 Km de Sumé) ou João Pessoa (capital do Estado com Campus da UFPB, e distante $250 \mathrm{Km}$ de Sumé), para dar continuidade aos seus estudos. O acesso ao ensino superior em outras localidades, durante décadas, foi uma situação comum para os jovens provenientes das classes média e alta dos municípios do interior da Paraíba, que geralmente se deslocavam para Campina Grande, João Pessoa, Areia, Bananeiras, Patos e Cajazeiras para cursar o ensino superior.

Neste contexto, colocamos como questões da pesquisa: Qual a contribuição da LeCampo CDSA para a formação docente e a prática pedagógica das escolas do cariri paraibano? Qual o perfil dos sujeitos que têm acessado a LeCampo? Qual a percepção destes sujeitos sobre as mudanças em sua prática pedagógica?

Para responder a estas indagações tivemos como objetivo geral da pesquisa: analisar a contribuição da LeCampo/UFCG para a formação docente e a prática pedagógica dos seus egressos. E, especificamente, tivemos como objetivos: caracterizar o perfil dos egressos do curso, dialogando com o que propõe o projeto político pedagógico do curso; identificar na percepção dos egressos como a formação no curso contribuiu para sua prática pedagógica nas escolas; e identificar se a proposta da LeCampo tem influenciado na organização do trabalho pedagógico nas escolas no campo do território.

\section{Trilhas e veredas metodológicas da pesquisa}

Para desenvolvermos a pesquisa, optamos pela abordagem qualitativa, por compreendermos que ela nos possibilitava visualizar e analisar a realidade social no campo educacional, em específico, e nos ajudava a desvelar os significados e concepções dos sujeitos pesquisados. Conforme descrito por Bogdan e Bilken (1994), os estudos qualitativos são marcados pela presença dos investigadores nos locais de estudo porque se preocupam em observar o ambiente da ocorrência dos fatos. 
Na sua busca de conhecimento, os investigadores qualitativos não reduzem as muitas páginas contendo narrativas e outros dados a símbolos numéricos. Tentam analisar os dados em toda a sua riqueza, respeitando, tanto quando possível, a forma em que estes foram registrados ou transcritos. (p. 48).

A investigação ação (Fals Borda, 1972), num diálogo permanente com a Educação Popular Freireana (1973, 1979, 1983), foi a referência para assegurar o caráter participativo da metodologia e possibilitar uma interação permanente entre os pesquisadores e os sujeitos representativos da situação investigada, não apenas como coadjuvantes dela, mas sim porque também são partes do objeto investigado, na sua construção e desdobramentos como egressos da Licenciatura em Educação do Campo.

Como instrumentos de pesquisa utilizamos o levantamento de dados secundários, questionário, a análise documental (Gil, 2008).

Um primeiro procedimento adotado na pesquisa foi o levantamento de dados secundários: acessamos os bancos de dados existentes na instituição, organizados por núcleos de pesquisa no CDSA, informações do Controle Acadêmico e da Gerência de Assistência Estudantil- GAE, o que nos possibilitou a construção do perfil dos egressos e a seleção dos sujeitos que iriam responder ao questionário semiestruturado, pois focamos nos egressos que estão inseridos em espaços educativos escolares (docência e gestão).

Para o processo de aproximação com os/as egressos/as realizamos, inicialmente, o levantamento no Controle Acadêmico da UFCG, do ano de formatura da primeira e última turma, o que nos possibilitou definir o recorte temporal de 2013-2019, mapear o número de formandos/as de cada período e suas respectivas áreas de conhecimento.

Um primeiro dado que se evidenciou neste levantamento foi referente à oferta, permanência e conclusão do curso. O que se torna importante para analisar a relevância deste curso para o atendimento da demanda por formação na região.

Identificamos que desde o primeiro vestibular, em agosto de 2009, até a última seleção, realizada em 2020, foram ocupadas 446 (quatrocentas e quarenta e seis) vagas das 600 (seiscentas) ofertadas. Isto representa uma ocupação de 74,33\% da oferta, o que reflete uma procura significativa pelo curso, visto que segundo o Censo da Educação Superior, no mesmo recorte temporal, no Brasil, a ocupação das vagas nas diversas Licenciaturas ficou em 20,5\%, sendo uma das mais procuradas a Licenciatura em Pedagogia (Brasil, 2019).

Dos quatrocentos e quarenta e seis que se matricularam no curso, $30,49 \%$ 
encontram-se atualmente matriculados, 10,3\% fizeram reopção de curso ou trancamento, 32,5\% evadiram-se do curso e $26,5 \%$ concluíram no período de 20132019, portanto, um percentual positivo, considerando que no mesmo período as Licenciaturas no Brasil apresentaram um percentual de 19,8\% de concluintes (Brasil, 2019).
No que se refere à questão da evasão, embora este índice encontre-se dentro da média das licenciaturas no Brasil, consideramos ser um fator importante de análise num próximo estudo, para uma análise das causas externas e internas deste fenômeno.

Tabela 1 - Número de matriculados, evadidos, cursando e concluintes da Lecampo - 2009-2019.

\begin{tabular}{|c|c|c|c|c|}
\hline ENTRADA & INGRESSANTE & EVADIDOS & CURSANDO & CONCLUINTES \\
\hline $\mathbf{2 0 0 9}$ & 50 & 08 & $X$ & 38 \\
\hline $\mathbf{2 0 1 0}$ & 22 & 08 & $X$ & 11 \\
\hline $\mathbf{2 0 1 1}$ & 49 & 20 & $X$ & 18 \\
\hline $\mathbf{2 0 1 2}$ & 49 & 25 & $X$ & 18 \\
\hline $\mathbf{2 0 1 3}$ & 44 & 23 & $X$ & 10 \\
\hline $\mathbf{2 0 1 4}$ & 34 & 14 & 01 & 11 \\
\hline $\mathbf{2 0 1 5}$ & 21 & 10 & $X$ & 09 \\
\hline $\mathbf{2 0 1 6}$ & 24 & 13 & 07 & 04 \\
\hline $\mathbf{2 0 1 7}$ & 28 & 11 & 17 & $X$ \\
\hline $\mathbf{2 0 1 8}$ & 45 & 13 & 32 & $X$ \\
\hline $\mathbf{2 0 1 9}$ & 40 & $X$ & 40 & $\mathrm{X}$ \\
\hline $\mathbf{2 0 2 0}$ & 40 & $\mathbf{X}$ & 39 & $\mathbf{1 1 9}$ \\
\hline TOTAL & $\mathbf{4 4 6}$ & $\mathbf{1 4 5}$ & $\mathbf{1 3 6}$ & $\mathbf{X}$ \\
\hline
\end{tabular}

Fonte: Controle Acadêmico sistematizado pelos autores, $2020^{\mathrm{v}}$. O uso do X significa que não tem nenhum daquele período cursando ou evadido.

Esse levantamento inicial já possibilitou uma primeira caracterização no que se refere à oferta-conclusão da Lecampo, assim destacamos:

A primeira entrada no curso foi por vestibular especial, no segundo semestre de 2009. No início de 2010 foi realizada outra entrada, seguindo as normas do vestibular da UFCG, na qual identificamos uma diminuição na entrada vinte e dois estudantes matriculados;
A partir de 2011, a entrada se deu via Enem, retomando o número de acesso significativo. Identificamos uma queda no acesso nos anos de 2014 a 2017, o que necessita uma maior análise posteriormente;

Os anos de 2011 a 2014 apresentam os maiores índices de evasão no curso, outra dimensão que também necessita de um estudo posterior para 
averiguar o que aconteceu nestes anos que contribuiu para estes dados;

A retomada do vestibular especial, a partir de 2018, já sinaliza um aumento na ocupação de vagas ofertadas, o que pode indicar algo positivo para 0 curso, bem como uma retomada do que estava proposto no seu projeto inicial. Todavia, coloca ainda um desafio para o projeto seletivo, que consiste em não trabalhar com o ENEM como um dos critérios para inscrição (mesmo que considere os últimos 6 anos, ainda percebemos que gera exclusão);

Outro fator que o vestibular especial vem indicando refere-se ao número de vagas reservadas para livre acesso e o sistema de cotas. Temos uma procura de inscrição e aprovação maior no que se refere às categorias de cotas, portanto superior ao número de vagas reservadas. Esta questão também gera uma exclusão porque ficamos nos dois últimos processos seletivos com vagas abertas na livre concorrência.

No que se refere aos períodos de 2019 e 2020, devido ao início da pandemia, e a conclusão da primeira etapa desta pesquisa, ainda não tínhamos os dados sobre evasão, relativos a estas duas entradas. Entretanto, tivemos informação que durante a pandemia estudantes destes dois períodos tenham evadido, devido às dificuldades de participação nas atividades de ensino remoto ou situações de doenças, mortes ou dificuldades financeiras nas suas famílias.

Estas informações nos colocaram alguns desafios na continuidade da discussão com o coletivo da Lecampo: adequação do processo seletivo da licenciatura, estudo sobre a evasão do curso, planejamento e acompanhamento dos estudantes durante a pandemia e quais as estratégias no retorno presencial.

Um segundo procedimento adotado na pesquisa foi a leitura $\boldsymbol{e}$ análise do Projeto Político Pedagógico do Curso $\boldsymbol{P P C}$, que nos possibilitou identificar as principais matrizes que orientam a formação docente e a prática pedagógica durante a formação docente, tais como: os sujeitos campesinos como referência da formação, a contextualização da educação, a articulação entre teoria $e$ prática, a alternância universidade/comunidades/escolas, a formação por área de conhecimento (interdisciplinaridade), a relação com os movimentos sociais e a articulação entre ensino, pesquisa e extensão durante toda a formação ${ }^{v i}$.

Um terceiro procedimento realizado apenas com os egressos que atuavam na docência e na gestão das escolas e das equipes pedagógicas das secretarias, foi o 
encaminhamento de um questionário semiestruturado, no formulário Google drive. Devido à pandemia não realizamos a entrevista e o grupo focal, antes planejado.

O questionário teve como finalidade identificar a concepção dos/as egressos/as sobre a contribuição da licenciatura para sua formação e sua prática profissional. O questionário foi aplicado com cinquenta e dois egressos/as, cujas falas estão identificadas no trabalho com as letras EG, e uma numeração conforme recebimento do questionário.

Durante o período de realização da pesquisa sempre nos orientamos pelos princípios da investigação ação (Fals Borda, 1972), com uma metodologia de pesquisa ação baseada na construção participativa do conhecimento, na qual o conhecimento se constrói em diferentes momentos e de diversas maneiras, com o objeto/sujeito, que possibilitou para a equipe de pesquisadores uma postura participativa e de interação dialógica com os sujeitos da pesquisa, que não se colocaram apenas como coadjuvantes dela, mas também participando de momentos formativos e de socialização de questões relacionadas ao objeto investigado.

Em virtude disto, seu objetivo transcende à mera quantificação de dados e fenômenos, focando no desvelamento da razão de ser dos meandros das relações sociais (Minayo, 2001; Ludke \& André, 1986). Os dados construídos a partir dos vários instrumentos foram analisados levando em conta as orientações e os procedimentos previstos na "análise de conteúdo". Para Bardin $(2016,48)$, a análise de conteúdo é:

Um conjunto de técnicas de análise das comunicações visando obter por procedimentos sistemáticos e objetivos de descrição do conteúdo das mensagens indicadores (quantitativos ou não) que permitam a inferência de conhecimentos relativos as condições de produção/recepção variáveis inferidas dessas mensagens.

\section{A interpretação e análise de dados} foram orientadas na Análise de Conteúdo (Bardin, 1977), via Análise Temática (Vala, 1986), apresentando os critérios de categorização, ou seja, escolha de categorias (classificação e agregação). Categoria, em geral, é uma forma de pensamento e reflete a realidade, de forma resumida, em determinados momentos. $\mathrm{Na}$ perspectiva da análise do conteúdo, as categorias são vistas como rubricas ou classes que agrupam determinados elementos, reunindo características comuns. Como resultado da sistematização dos resultados no relatório de pesquisa, buscaremos propor um planejamento de ações e atividades no coletivo do curso, como uma resposta às informações encontradas na pesquisa. 
A percepção dos egressos: contribuição para a formação e prática pedagógica

A reflexão sobre a contribuição da Licenciatura em Educação do Campo Lecampo/UFCG/CDSA gerada pela pesquisa com os/as egressos/as pautou-se inicialmente pelo aprofundamento do seu surgimento no território do Cariri, como resultado de duas mobilizações sociais, políticas e educacionais: uma primeira, a articulação com o Movimento Nacional da Educação do Campo, que traz a luta camponesa como matriz pedagógica importante para seu Projeto Político Pedagógico e a segunda a materialização da política de desenvolvimento territorial e do Projeto Unicampo, que traz a territorialidade e os sujeitos coletivos do Cariri Paraibano como contexto e autores da proposta (CDSA, 2009). Assim,

A decisão política de lutar pela formação de educadores/as do campo em cursos superiores, como um direito desses sujeitos a sua formação inicial e continuada crítica e contextualizada na prática pedagógica das escolas do campo. A escola constitui-se em um espaço de sociabilização para o homem/mulher do campo, na medida em que reforça essas relações, que contribuem para a consciência de si e de classe, para a construção de conhecimentos outros. (Silva, 2019, p. 235).

Neste sentido, a proposta de curso considerou todo esse debate nacional, as questões levantadas pela realidade do
Semiárido, as demandas dos movimentos sociais e a política assumida no atual governo pela SECAD/MEC, avaliando ser fundamental colaborar para a consolidação de uma Política de Educação do Campo, propondo contribuir através da oferta de Curso de Licenciatura em Educação do Campo, destinado prioritariamente aos professores (as) e outros profissionais que atuam nas práticas educativas escolares e não escolares do campo, bem como a jovens concluintes do ensino médio e oriundos das comunidades rurais do território (CDSA, 2009).

Certamente, as Licenciaturas pilotos efetivadas em $2007^{\text {vii }}$ tiveram características distintas das que se organizaram pelo Procampo, em 2009, ou no edital de 2012. A Lecampo/UFCG já foi criada como um curso regular da UFCG, sendo uma das primeiras que se organiza no Brasil institucionalizada na matriz Andifes.

\section{Resultados e discussão}

Para a análise dos dados coletados durante a pesquisa fizemos uma categorização a partir das seguintes temáticas: perfil dos egressos, contribuição da proposta do curso para a formação $e$ organização do trabalho pedagógico e a 
percepção dos egressos e como materializam os princípios da Lecampo na sua formação e prática.

\section{Perfil dos Egressos da Licenciatura em Educação do Campo da UFCG/CDSA}

Uma primeira caracterização foi referente à vinculação territorial dos egressos, para identificar o atendimento da demanda da região pela Lecampo, visto que no PPC do curso existe uma clara definição de priorizar, inicialmente, os municípios do cariri paraibano e regiões circunvizinhas.

Tabela 2 - Municípios de origem dos egressos da Lecampo - 2013-2019.

\begin{tabular}{|l|c|}
\hline Municípios & Quantidade \\
\hline Amparo & 04 \\
\hline Caraúbas & 01 \\
\hline Coxixola & 01 \\
\hline Livramento & 02 \\
\hline Ouro Velho & 01 \\
\hline Parari & 01 \\
\hline Prata & 02 \\
\hline São João do Cariri & 06 \\
\hline São João do Tigre & 01 \\
\hline São José dos Cordeiros & 04 \\
\hline Serra Branca & 19 \\
\hline Sumé & 73 \\
\hline São José do Egito (Pajeu Pernambuco) & 01 \\
\hline Itaporanga (Sertão Paraibano) & 01 \\
\hline Santa Cruz do Capibaribe (agreste Pernambucano) & 01 \\
\hline Total & $\mathbf{1 1 9}$ \\
\hline
\end{tabular}

Fonte: GAE/CDSA, sistematizado pelos autores, 2020.

A Tabela 2 nos mostra que os las egressos/as são provenientes prioritariamente do cariri paraibano e até o período estudado temos 12 (doze) municípios com Licenciados/as em Educação do Campo. Sumé, como município sede do CDSA, é o que apresenta o maior número 73 (setenta e três), seguido de Serra Branca, com 19 (dezenove). Apenas três são provenientes de outras regiões - sertão paraibano, agreste e Pajeú Pernambucano. Estes dados contribuem para que possamos pensar o processo de divulgação do curso no Sertão de Pajeú, região fronteiriça do Cariri, que embora tenha a presença do Instituto Federal de Educação, não possui Licenciatura, apenas cursos tecnológicos.

Uma segunda dimensão analisada foi a origem sócio familiar dos egressos, visto que o PPC define como público prioritário: jovens e adultos provenientes da classe trabalhadora do campo e professores/as em exercício nas escolas no 
campo. Podemos identificar entre os egressos 2013-2019 que 46,9\% dos egressos são oriundos de família de agricultores familiares e assentados da Reforma Agrária, que produzem, principalmente: milho, feijão e mandioca e horticultura de verduras e legumes, mas recentemente surge também o algodão agroecológico, principalmente no Assentamento Zé Marcolino; 21,9\% dos/as egressos \as são filhos de pais que realizam a criação de animais (predominando a caprinocultura); $10 \%$ são oriundos de famílias de pescadores artesanais, apicultores, artesanato; e $20 \%$ são distribuídos em atividades na área de educação, comércio, serviços públicos municipais e aposentadoria rural.

Portanto, a maioria dos egressos são provenientes de famílias campesinas, e mesmo os que residem ou desenvolvem atividades na sede dos municípios, a marca de forte ruralidade neste território estabelece um vínculo muito forte com a terra e a produção agrícola.

No que se refere ao sexo dos sujeitos, o gráfico 1 nos mostra que dos cento e dezenove egressosłas, setenta são do sexo feminino e quarenta e nove são do sexo masculino.

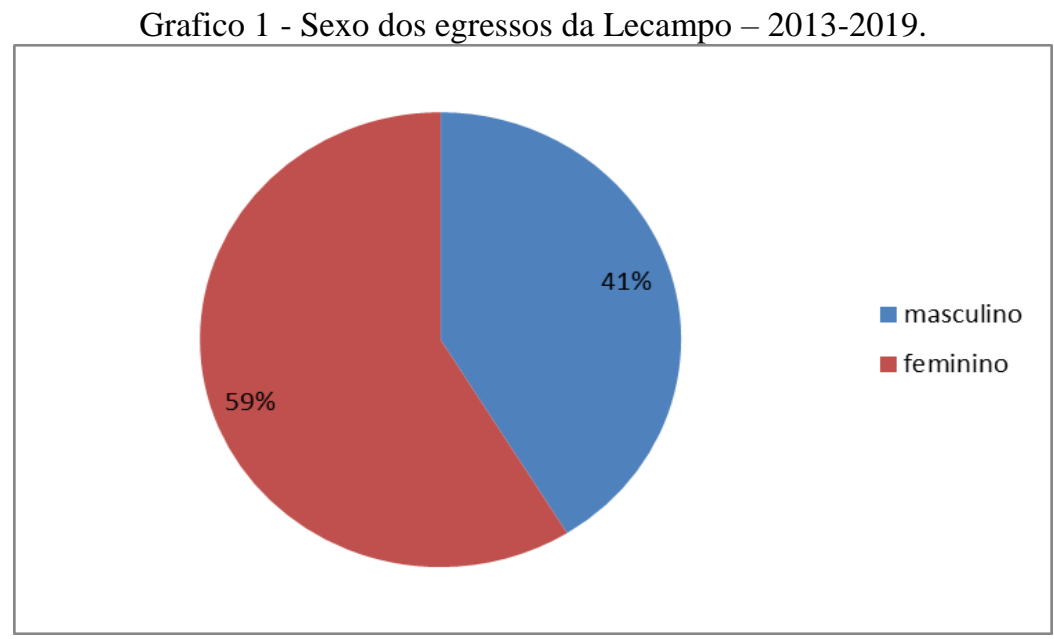

Fonte: Controle Acadêmico UFCG, sistematizado pelos autores, 2020.

Historicamente no Brasil, as licenciaturas se constituem majoritariamente pelo sexo feminino. No Brasil, o percentual é de $71,3 \%$ do sexo feminino e $28,7 \%$ do sexo masculino, nas licenciaturas. A Lecampo apresenta um percentual de 59\% do sexo feminino e $41 \%$ do sexo masculino, distribuídos nas três áreas de conhecimento do curso: Ciências Humanas e Sociais, Linguagens e Códigos e Ciências da Natureza e da Matemática. 
No que se refere às egressas da área de Ciências da Natureza e da Matemática, um dado que chamou a nossa atenção, e que carece de um debate no curso sobre o recorte de gênero, nas áreas de conhecimento, foi o de que das catorze formandas na área: três não atuaram em Educação, uma tem atuação profissional na área de saúde, três têm atuação na Educação Infantil e anos Iniciais do Ensino Fundamental, seis têm atuação em programas e projetos governamentais (Mais Educação, Projovem Campo Saberes da Terra), e apenas uma tem atuação como professora do Ensino Médio na área.

No que se refere a faixa etária dos egressos percebemos pelo gráfico 2 que temos $71 \%$ dos concluintes entre 21 e 30 anos, o que representa um profissional com um perfil jovem, o que leva a uma renovação geracional na categoria docente no campo.

Gráfico 2 - Faixa etária dos egressos da Lecampo 2013-2019.

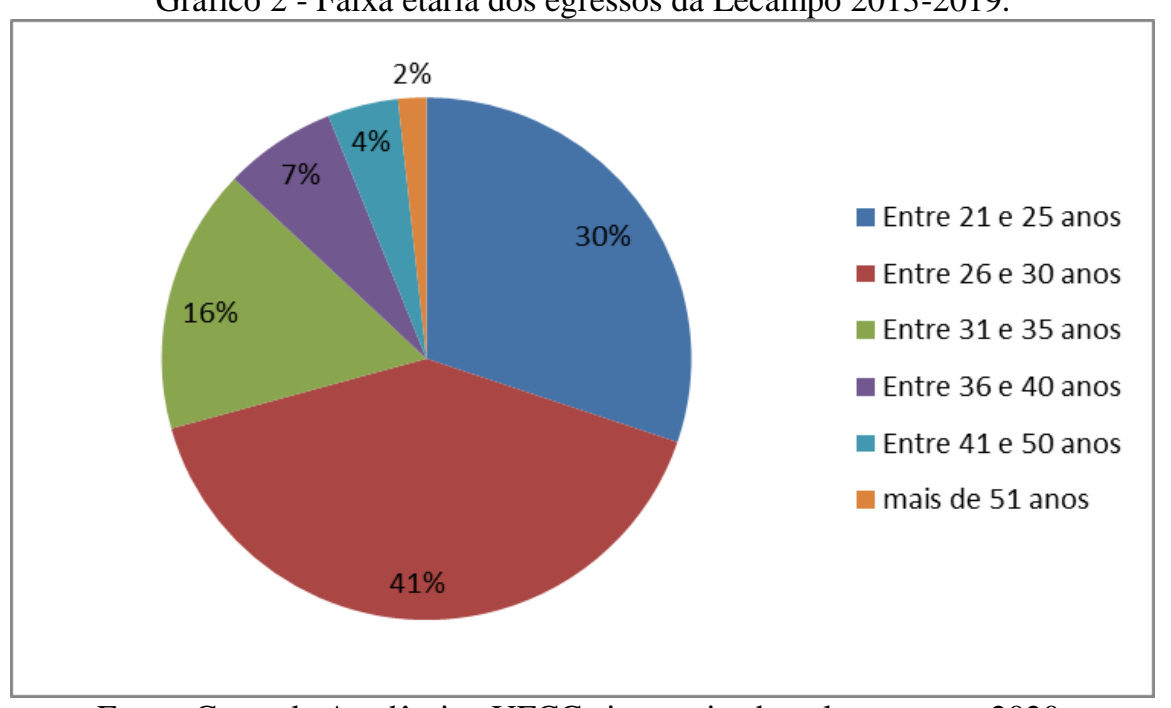

Fonte: Controle Acadêmico UFCG sistematizado pelos autores, 2020.

Considerando a faixa etária de $86 \%$ dos egressos até 35 anos de idade, pressupõe-se tempo de atuação profissional como futuro significativo, o que pode gerar uma contribuição importante na prática das escolas do território.

No que se refere à área de formação do/as egressos/as, constatamos que a área que mais formou docentes foi a de Ciências Humanas e Sociais, seguida da área de Linguagens e Códigos e, por fim, da área de Ciências da Natureza e da Matemática. Considerando que os dados nacionais evidenciam a carência de docentes na área das Ciências Exatas, como essa tem sido uma área de menor procura e conclusão dentro do Curso, tal fato sinaliza para uma reflexão com o coletivo. 
Gráfico 3 - Percentual de egressos las por área de conhecimento - 2013-2019.

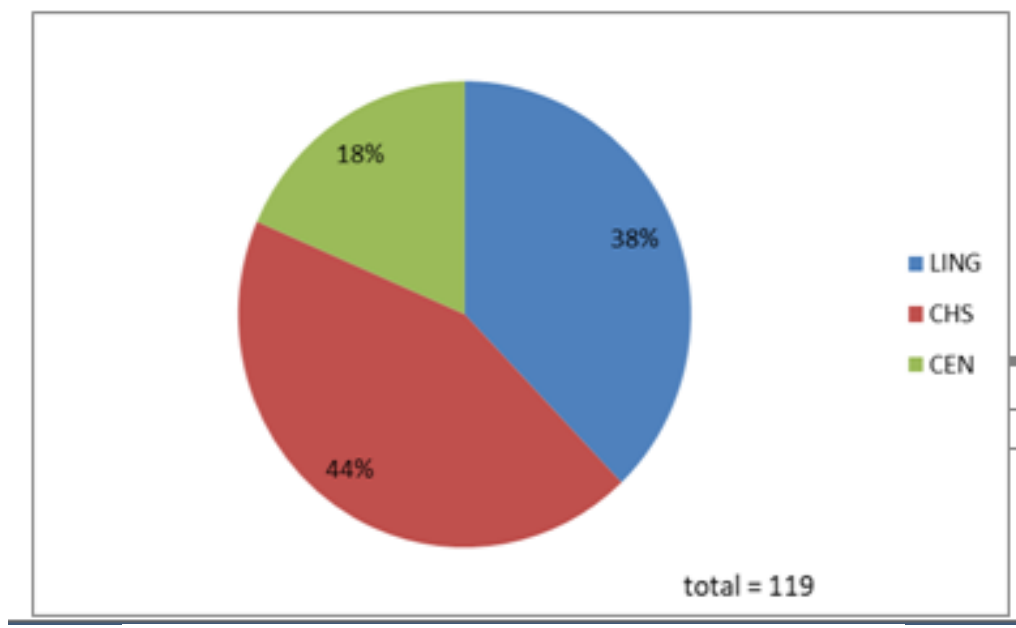

Fonte: GAE/CDSA, sistematizado pelos autores, 2020

Este processo inicial de aprofundamento sobre a área de conhecimento torna-se importante porque $60 \%$ dos egressos/as afirmam que possuíam pouca informação quando ingressaram no curso e 22\% não possuíam nenhuma informação. A escolha pelo curso foi motivada principalmente por: oportunidades de campo de trabalho no magistério, e o curso fazer referência ao campo, o que dialogava com sua origem social e familiar.

\section{A contribuição dos fundamentos e princípios da Proposta da Lecampo na sua formação inicial e continuada}

Uma primeira questão que aparece na análise das respostas dos egressos foi a pouca informação que possuíam sobre o curso quando ingressaram. Talvez pelo fato de ser a primeira geração de formados neste perfil profissional, portanto, um curso desconhecido, não apenas no território, mas no país. Assim, 60\% possuíam pouca informação sobre o curso, e 22\% não possuíam nenhuma informação. A escolha por ele foi decorrente do magistério sempre ter campo de trabalho e por gostar da área de educação. Todavia, ressaltam como esta relação foi se modificando ao longo do curso. Vejamos:

A Lecampo me fez ter contato com realidade do nosso Cariri que até ter contato com o curso não tinha nenhum tipo de conhecimento. Assim como também foi através da Lecampo que tive experiências em sala de aula antes mesmo de concluir o curso. (EG 07).

Mas a experiência de ter cursado um curso em uma Universidade Federal, no CDSA um dos mais conceituados, e ainda ter feito parte da turma de egresso da Lecampo, foi simplesmente singular em minha vida. E acredito que a cada dia que se passa as possibilidades de inserção no mercado de trabalho serão ampliadas para nós Licenciados em Educação do Campo. Nossa organização como egresso é 
fundamental para isto acontecer. (EG 21)

Um desses desafios é a formação e atuação profissional por área de conhecimento, que vem romper com a lógica disciplinar posta pela tradição pedagógica tradicional. No que se refere à formação recebida no curso para a prática pedagógica por área de conhecimento, tivemos o seguinte resultado:

Gráfico 4 - Conhecimentos na formação sobre a área.

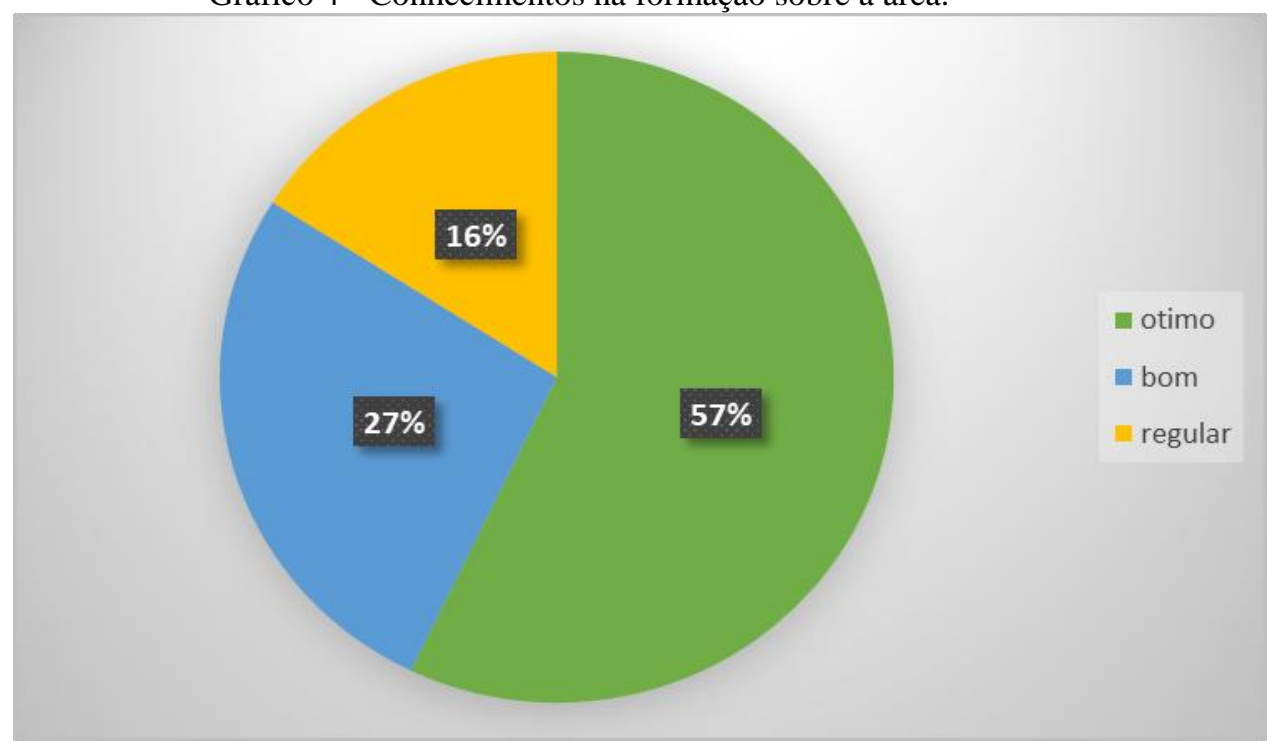

Fonte: sistematizado pelos autores, 2020.

Os/as egressos/as sinalizaram que os/as docentes formadores da Licenciatura também estão buscando aprofundar a forma de trabalhar por área de conhecimento, colocando também que, no princípio, tiveram muita dificuldade de entender como trabalhar dessa forma interdisciplinar, contextualizada e integrada, sinalizando que a experiência no Programa de Iniciação à Docência - Pibid Diversidade contribuiu muito prática pedagógica contextualizada. Vejamos o depoimento:
Por ser um curso interdisciplinar tem diversos pontos positivos, um deles a maior possibilidade de inserção no mercado de trabalho, mas também se torna um ponto negativo PR ser um curso novo onde pouco é citado nos concurso e processos seletivos (EG 15).

No que se refere à formação recebida na Lecampo, $75, \%$ avaliam que a formação teórica recebida no curso possibilita um bom conhecimento sobre o campo, os movimentos sociais, os fundamentos da educação, a organização do trabalho pedagógico, destacando o papel da iniciação à docência no Pibid Diversidade e da participação na extensão 
pelo Probex na sua formação. Vejamos o depoimento abaixo:

Sim. Porque a Lecampo é um curso interdisciplinar que tanto visa formar os professores que já estão em exercício nas escolas do cariri, e também é aberto para quem tenha interesse na atuação docente. Além disso, é uma proposta formativa em várias áreas de conhecimentos, que contribui para a construção de conhecimentos, e a valorização do contexto onde vive. (EG 01)

Os/as egressos/as consideram que a formação específica na área de conhecimento possibilita um bom aprofundamento nos conteúdos a serem trabalhados, e $70 \%$ destes consideram adequada a escolha da área somente no quarto período, porque já possuem reflexões sobre a Educação do Campo, e um maior contato com as escolas nas comunidades rurais, o que é possível pelos Laboratórios de Pesquisa e na participação nos projetos de extensão, contudo, 30\% defendem que a escolha deveria ser no vestibular para direcionar os estudos. Vejamos, as falas:

Acredito que a formação especifica é boa sim, apesar das dificuldades dos concursos por área de conhecimento, os profissionais saem bem preparados, e assim o curso alcança os objetivos, cabe a nós lutar por oportunidade. Temos um longo caminho pelo frente para lutar por uma organização curricular diferente nas escolas (EG 10)
O curso é muito bom, mas precisaríamos de um aprofundamento maior da área de conhecimento. Por exemplo, como egresso de Linguagens acho que deveria escolher uma lingua estrangeira para aprofundar mais durante o curso. Além disso antes tinha também curso de extensão em língua estrangeira que ajudava muito (EG 25)

Quando solicitados a destacar os componentes curriculares que mais contribuíram para sua prática, além dos componentes da formação específica (cada área de conhecimento), se destacou os estágios supervisionados, os Lapecs ${ }^{\text {viii }}$ e a participação em projetos. Vejamos os depoimentos:

Os estágios do curso, minha atuação no PIBID e do tempo em sala de aula tive uma excelente formação, apesar de não ministrar aula recentemente por motivos maiores, conseguir realizar o meu sonho e obter minha formação (EG 17).

Os Lapecs quando bem trabalhados nos ajudam a conhecer as comunidades, as organizações, as escolas, as professoras que estão nas escolas nos sítios e nos assentamentos. Antes eu nem conhecia tantas práticas que existem em meu município. (EG 28)

Tanto os estágios como Lapecs foram muito importantes para minha formação. Agora tem que ter supervisão/orientação nestes dois, ou seja, o professor que ficar com eles tem que acompanhar mesmo a gente, tem que ir em campo, senão não funciona. (EG 31) 
Todavia, como consideram Estágios Supervisionados e Lapecs como importantes para articulação com as comunidades e as práticas nas escolas, sugerem que possam ser repensados, numa reformulação curricular, para que se aprofunde mais nas questões relacionadas: a relação com as comunidades, com os movimentos sociais e com o planejamento e a avaliação da aprendizagem.
No que se refere à contribuição da Lecampo

com metodologias/estratégias/ferramentas para interação com as famílias e as comunidades, destacou-se que é preciso um maior aprofundamento no curso, pois tivemos o seguinte resultado:

Gráfico 5 - Contribuição da Lecampo com estratégias\ferramentas para interaçãoไtrabalho com a comunidade camponesa.

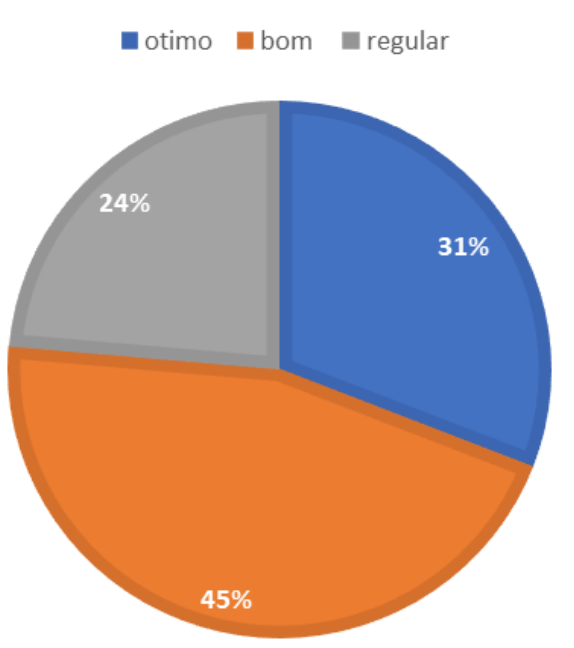

Fonte: questionário da pesquisa, sistematizado pelos autores, 2020.

\section{A necessidade de continuar}

estudando apareceu na fala de 90\% dos/as egressos/as, na formação continuada, na pós-graduação, ou mesmo numa segunda licenciatura, enfatizaram que este 'gosto pelo estudo' e pesquisar foi despertado na Lecampo. Vejamos a tabela 3:

Tabela 3 - Concluiu/Cursando outro curso - egressos/as Lecampo 2013-2019.

\begin{tabular}{|l|c|}
\hline \multicolumn{1}{|c|}{ Curso } & Quantidade \\
\hline Cursando outra licenciatura (Pedagogia/Letras/Educação Física) & 07 \\
\hline Concluiu outra licenciatura (Pedagogia/Educação Física/Libras) & 09 \\
\hline Concluiu Especialização (EJA/CEN/Letras/Libras) & 21 \\
\hline
\end{tabular}




\begin{tabular}{|l|c|}
\hline Cursando Especialização (ECSAB) & 15 \\
\hline Concluiu Mestrado & 03 \\
\hline $\begin{array}{l}\text { Cursando Mestrado (Educação/Profsocio/Literatura e } \\
\text { Interculturaidade) }\end{array}$ & 07 \\
\hline Total & $\mathbf{6 2}$ \\
\hline
\end{tabular}

Fonte: Pesquisa de Campo, sistematizado pelos autores, 2020.

Os/as egressos/as ressaltam também a participação nas formações continuadas dos municípios, participação em atividades dos projetos de extensão do CDSA junto às redes municipais, destacando o "Curso de Aprofundamento do Escola da Terra", que possibilitou um maior conhecimento das Escolas/turmas multisseriadas, o debate sobre o fechamento de escolas e a necessidade de elaboração de uma proposta específica que contemple a heterogeneidade destas turmas.

\section{Percepção dos/as egressos/as de como materializam os princípios da Lecampo na prática pedagógica: mudanças na organização do trabalho pedagógico}

A entrada de um novo perfil profissional no campo de trabalho tem ocorrido tanto em escolas no campo, como também em escolas nas sedes dos municípios - que possuem no território do cariri, uma ruralidade social, econômica e cultural muito forte. A atuação profissional dos/as egressos/as tem sido avaliada de forma positiva tanta na docência como na gestão nas escolas que estão exercendo seu trabalho, neste sentido, mudanças nas práticas das escolas começam a ser percebidas nos municípios. Vejamos as falas abaixo:

Contribuiu significativamente na medida em que construiu uma nova perspectiva de formação docente na região. Essa nova visão de educação que a Lecampo trouxe para o Cariri contribuições riquíssimas em vários aspectos das discussões curriculares, da participação da comunidade e dos estudantes nas escolas (EG 03)

Sim, Primeiro por engajar a juventude de nossa região, seguir os passos da docência. Segundo, em vários momentos nossa Licenciatura dialoga diretamente com a sociedade, seja com formações continuadas com professores(as), projetos de extensão, busca a interação como os movimentos sociais da região, formações que colaboram para o desenvolvimento pleno da nossa região. (EG 09)

Essa entrada no campo de trabalho se constitui num desafio, visto que nem todos os municípios da região, abriram concurso público ou contratos temporários específicos para o perfil da Educação do Campo. Portanto, temos uma inserção profissional diversificada, vejamos a tabela 4. 
Tabela 4 - Campo de atuação dos egressos da Lecampo, 2013-2019.

\begin{tabular}{|l|c|}
\hline \multicolumn{1}{|c|}{ Campo de atuação } & Quantidade \\
\hline Escola (docência ou gestão) & $\mathbf{5 2}$ \\
\hline $\begin{array}{l}\text { Não escolar (movimentos sociais, conselhos, agentes de saúde, arte e } \\
\text { cultura, programas governamentais vinculados à educação, reforço escolar). }\end{array}$ & $\mathbf{2 0}$ \\
\hline Trabalha em outros setores não vinculados à escola & $\mathbf{1 9}$ \\
\hline Total & $\mathbf{9 1}$ \\
\hline
\end{tabular}

Fonte: Pesquisa de Campo, sistematizado pelos autores, 2020.

Dentre os/as que estão atuando na escola buscamos identificar em que etapa ou modalidade da Educação. Vejamos o que nos mostra a tabela 5 .

Tabela 5 - Exercício profissional dos egressos na docência ou gestão da educação - 2013-2019.

\begin{tabular}{|l|c|}
\hline \multicolumn{1}{|c|}{ Exercício profissional } & Quantidade \\
\hline Educação Infantil & 04 \\
\hline Anos Iniciais do Ensino Fundamental & 04 \\
\hline Educação de Jovens e Adultos & 06 \\
\hline Anos Finais do Ensino Fundamental & 16 \\
\hline Ensino Médio & 06 \\
\hline Gestão Escolar & 04 \\
\hline Coordenação Pedagógica & 07 \\
\hline Técnico ou apoio administrativo & 04 \\
\hline Educação Especial (libras) & 01 \\
\hline Total & $\mathbf{5 2}$ \\
\hline
\end{tabular}

Fonte: Pesquisa de campo, sistematizado pelos autores, 2020.

Do total de egressos/as, 28 (vinte e oito) colocaram que não estão trabalhando, e 19 (dezenove) que trabalham em outros setores que não a escola (comércio, hospital, transporte, agricultura). Estes dados continuam desafiando a organização e luta no território para inserção destes profissionais no campo de trabalho para que foram formados.

Sobre a dificuldade de inserção no campo de trabalho por área de conhecimento, as falas seguintes são representativas do grupo. Vejamos:

Concordo, o profissional saí preparado para o campo de trabalho, porém não existe vagas suficientes devido à falta de compromisso de muitos gestores com esse tipo de profissional, infelizmente tem que partir para outras áreas ou etapas da Educação Básica. Nem todos os municípios do território estão abrindo vagas para a inserção do Licenciado em Educação do Campo. Essa é nossa luta daqui por diante. (EG 16) As oportunidades de trabalho são por tempo limitado, ou seja, por contrato temporário, ou então quando surge um Programa do Governo, logo abre 
para nosso perfil, porque sabe que nós estamos preparados para realizar este trabalho, e dá conta da proposta. Seguimos na intenção de recorrer a concursos públicos para nos efetivar enquanto profissionais da Educação do Campo, na nossa região. (EG 12)

Essas inquietações geraram, entre os egressos, diferentes formas de mobilização: elaboração de informação sobre o curso para encaminhar às prefeituras, discussão nas câmaras de vereadores dos municípios, divulgação nos meios de comunicação, reivindicação junto às prefeituras municipais e o governo do Estado para inserção do perfil dos egressos nos concurso público dos municípios e do Estado da Paraíba.

Identificamos que, gradativamente, os egressos começaram a ocupar o campo de trabalho para que foram formados, o que, certamente, tem relação com os concursos que foram realizados em três municípios e na rede estadual, considerando a docência, anos finais do ensino fundamental e ensino médio e na gestão escolar (gestor e coordenação pedagógica), com a formação especifica da Licenciatura.

No que se refere à prática docente e gestora, os/as egressos/as foram questionados para uma autoavaliação do seu trabalho e a maioria respondeu que está conseguindo fazer mudanças na sua prática e na escola. Algumas dimensões destacadas:

a) mudança no planejamento e a interdisciplinaridade: os/as egresso/as avaliam que estão conseguindo realizar mudanças nas escolas e responderam positivamente à questão da interdisciplinaridade, de diferentes tempos e espaços para o trabalho pedagógico e avaliação da aprendizagem foram destacados como princípios e práticas importantes aprendidos durante a formação. Vejamos os depoimentos:

Sim. A minha formação na Lecampo contribuiu para minha organização para exercer a docência passou a ter novas formas de pensar e agir depois dessa formação. Passei a organizar melhor os meus planejamentos, considerar os conhecimentos e melhor integra-los, compreender e colocar em pratica o ensino integrando as áreas do conhecimento por meio dos temas, das pesquisas, considerar espaços dentro e fora da escola como espaços educativos, desenvolver materiais de apoio pedagógicos que venha facilitar a aprendizagem, proporcionou diferentes formas de avaliar o desenvolvimento dos meus educandos, me fez perceber e valorizar em sala os conhecimentos que os meus educandos trazem da família, da comunidade e me fez despertar para metodologias participativas com o desenvolvimento de aulas com musica, brincadeiras, jogos, danças, etc. (EG 12) 
b) O Trabalho coletivo foi destacado por $75 \%$ dos/as egressos/as como um aprendizado e um princípio importante para o trabalho docente nas escolas, pois o coletivo docente contribui para transformação da escola, para aprender junto como trabalhar por área de conhecimento, para contextualização dos conteúdos, para interagir com os estudantes e suas famílias. Assim,

A Lecampo foi de suma importância na minha vida profissional e minha participação coletiva e social, levando a uma reflexão sobre a prática docente $\mathrm{x}$ contextualização seja ela no campo ou na cidade. Ajuda a pensar o trabalho coletivo na escola e na comunidade. Dessa forma podemos perceber a importância da Lecampo seja ela nas escolas nas sedes dos municípios ou nas comunidades rurais. sendo este um curso que dialoga diretamente com as práticas vivenciadas no dia a dia dos educandos, e também considera-los como sujeitos de conhecimento (EG 16)

Aprendi muito com o trabalho coletivo, a organização dos estudantes, das turmas, dos professores do curso, uma das coisas que mais me marcou enquanto estudante da Lecampo, que trouxe para minha prática, não foi só as disciplinas ou as discussões das teorias sobre educação... mas a postura dos professores em relação ao que diziam, defendiam e faziam, aprendi mais observando e praticando, do quê só ouvindo teorias... trouxe para minha prática, perceber o outro, olhar além do que se apresenta, aprender a ouvir, a estender a mão, a lutar pelo que acredita e acima de tudo, respeitar as opiniões adversas a sua formação humana, foi o que mais me marcou na Lecampo (EG 23)

Assim, identificamos que a formação na Lecampo possibilita o debate acerca da prática pedagógica nas escolas do campo, envolvendo diferentes sujeitos: professores(as), gestores, pais, estudantes numa indagação sobre o modelo de escola existente em sua comunidade, em seu município, com a elaboração de propostas e práticas pedagógicas que valorizam na organização da escolaridade, diversidade dos sujeitos existentes no campo, a cultura da comunidade, os processos de transformação do campo, a gestão democrática das escolas e a produção e sistematização de conhecimentos contextualizados a realidade.

\section{Conclusão}

A perspectiva crítica adotada na pesquisa nos ajudou a problematizar o contexto social e educacional do território, identificar o perfil dos egressos, compreender as relações que se estabelecem nos municípios com a formação deste novo perfil profissional, o acesso à profissão a partir dos concursos públicos, a luta pela existência da escola de anos finais do fundamental e ensino médio nas comunidades rurais e as contradições 
postas por uma prática docente organizada a partir das áreas de conhecimento.

Identificamos na fala dos egressos como o debate sobre o projeto de sociedade e de campo perpassa toda a discussão sobre a organização curricular e a metodologia utilizada nas escolas e salas de aula. Atribuem a formação que receberam na Licenciatura o conhecimento e a reflexão sobre a teoria da educação que contribui para uma educação fundada na formação e emancipação humana, por isto, colocam que é fundamental se planejar a organização do trabalho escolar, o trato com o conhecimento, a organização do tempo e do espaço, as relações entre os diferentes sujeitos da escola, o conjunto de saberes que são necessários para o sujeito docente e gestor realizarem o seu trabalho e como, nas atividades de ensino e aprendizagem, articulam-se os diferentes dispositivos para atingir os objetivos e finalidades desta educação emancipatória.

A valorização dos saberes populares num diálogo com os conhecimentos científicos na prática pedagógica dos egressos produziram muitos frutos, desencadeando mudanças significativas nos processos administrativos e pedagógicos das escolas, nas quais a participação da família e da comunidade passa pela organização coletiva de educandos (as), educadores(as), técnicos administrativos, comunidade e pelo envolvimento efetivo de outros sujeitos do processo de ensinar-aprender vivenciado na escola e na comunidade.

Assim, os caminhos construídos pelas práticas dos egressos nas escolas são múltiplos, no entanto, carregam o potencial de gerar um conhecimento e uma itinerância que sinalizam para práticas que buscam responder a realidades dos sujeitos sociais a quem se destinam e que se constituem como um processo situado em um tempo e em um espaço específicos, com diferentes formas organizativas do trabalho escolar

Assim, desvelar aquilo que ainda não é inteligível, que passa despercebido, revelar as suas nuances, propor caminhos construídos coletivamente parece ter sido o rumo e a maior contribuição da Licenciatura, pois possibilitou a entrada e a formação de jovens no ensino superior, direito até então negado.

Desse modo, fica evidente que a mais importante justificativa deste projeto é assegurar o direito público subjetivo dos sujeitos do campo ao acesso a educação superior, aliado ao histórico e acúmulo acadêmico desta IES, a qual tem demonstrado grande êxito na formação de professores(as), inclusive dos que atuam na área rural do Estado, explicitando mais uma vez seu 
compromisso com o fortalecimento da autonomia e da Universidade enquanto espaço público de produção de conhecimento.

\section{Referências}

Bardin, L. (2010). Análise de conteúdo. Edições 70, LDA. Lisboa.

Bogdan, R., \& Biklen, S. (1994). Investigação qualitativa em educação: uma introdução à teoria e aos métodos. Lisboa: Porto Editora.

Brasil. (2019). Instituto Nacional de Estudos e Pesquisas Educacionais Anísio Teixeira (INEP). Censo da Educação Superior 2018: notas estatísticas. Brasília.

CDSA. (2009). Projeto Político Pedagógico da Licenciatura em Educação do Campo-PPC Lecampo.

Caldart, R. S. (2008). Sobre educação do campo. In Santos, C. A. (Org.). Educação do campo: campo - políticas públicas educação (pp. 67-86). Brasília: Incra/MDA.

Caldart. R. S. (2009). Educação do campo: notas para uma análise de percurso. Trabalho, Educação e Saúde, 7(1), 35- 64. https://doi.org/10.1590/S198177462009000100003

Fals Borda, O. (2010). Da pedagogia do oprimido à pesquisa participativa. In Streck, D. (Org.) Fontes da Pedagogia Latino-Americana: uma antologia. Belo Horizonte: Autêntica Editora.

Freire, P. (1973). Pedagogia do Oprimido. 17. ed. Rio de Janeiro: Paz e Terra.
Freire, P. (1983). Pedagogia da autonomia: saberes necessários à prática educativa. São Paulo: Paz e Terra.

Gamboa, S. S. (1995). Pesquisa educacional: quantidade/qualidade. São Paulo: Cortez.

Gil, A. C. (2008). Métodos e Técnicas de Pesquisa. São Paulo: Atlas.

IBGE. (2000). Instituto Brasileiro de Geografia e Estatística. Censo Demográfico. Brasil.

Kolling, E. J., Nery, I., \& Molina, M. C. (1999). Por uma educação básica do campo (memória). Brasília: Articulação Nacional por uma Educação do Campo.

Ludke, M., \& André, M. E. D. A. (1986). Pesquisa em educação: abordagens qualitativas. São Paulo: EPU.

Minayo, M. C. S. (1994). Ciência, técnica e arte: o desafio da pesquisa social. In Minayo, M. C. S. (Org.). Pesquisa social: teoria, método e criatividade (pp. 9-29). Petrópolis: Vozes.

Minayo, M. C. S. (2010). O desafio do conhecimento: pesquisa qualitativa em saúde. São Paulo: HUCITEC.

Molina, M. C., \& Hage, S. (2015). Política de formação de educadores do campo no Contexto da expansão da educação superior. Revista Educação em Questão, 51(37), 121-146. https://doi.org/10.21680/19811802.2015v51n37ID7174

Silva, M. S. (2009). As práticas pedagógicas das escolas do campo: a escola na vida e a vida como escola (Tese de Doutorado). Recife: UFPE.

Silva, M. S. (2019). Educação do Campo e sua institucionalidade: o fio da navalha pela criação e institucionalização das 
Licenciaturas em Educação do Campo. In Formação de Formadores: Reflexões sobre as experiencias da Licenciatura em Educação do Campo no Brasil (pp. 233248). Belo Horizonte: Autêntica Editora.

Vala, J. (1986). A análise de conteúdo. In Silva, A. S., \& Pinto, J. M. (Orgs.). Metodologia das ciências sociais (pp. 101128). 8.ed. Porto: Afrontamento.

${ }^{\text {i }}$ O resumo simples deste artigo foi publicado nos Anais eletrônicos do evento de Iniciação Cientifica de 2020 da UFCG.

ii O documento preparatório da primeira Conferência Nacional Por uma Educação Básica do Campo (Caldart, 2004, p. 25) define povos do campo como o conjunto dos trabalhadores e das trabalhadoras do campo, sejam camponeses, agricultores, criadores, extrativistas, pescadores, ribeirinhos, caiçaras, quilombolas, seringueiros, indígenas, posseiros, arrendatários, meeiros, trabalhadores assalariados e suas famílias, vinculados à vida e ao trabalho no meio rural.

iii No ano 2002 ocorreu o desmembramento da Universidade Federal da Paraíba - UFPB e vinculados à Universidade Federal de Campina Grande ficaram os Campus dos municípios de: Campina Grande, Patos, Sousa e Cajazeiras. Em 2006, com a interiorização, foram criados os campus de Pombal, Cuité e Sumé.

iv A ideia de implantar uma "Universidade Camponesa" (UC) no Brasil surgiu no ano de 2000 a partir do interesse da CONTAG em formar os seus quadros com o suporte da universidade e da cooperação internacional, tomando-se como modelo a experiência da Université Paysanne Africaine.

${ }^{v}$ Dois estudantes falecidos durante o curso período de 2009 e 2014 e quarenta e seis estudantes fizeram reopção por outro curso ou trancamento do curso.

vi Essas categorias serão objeto de análise mais detalhada na continuidade dos estudos sobre a temática.

vii A partir do debate entre movimentos sociais do campo e as universidades, ligadas à Educação do Campo (UFMG, UnB, UFBA e UFS), começam as experiências pilotos das Licenciaturas no Brasil. A Lecampo da Universidade Federal de Minas Gerais é a mais antiga, se institucionalizando como um curso regular em 2009.

viii O Laboratório de Pesquisa e Prática em Educação do Campo é um componente curricular ofertado do primeiro ao quinto período do curso, tendo como finalidade organizar e coordenar o tempo comunidade dos estudantes, bem como aprofundar questões vinculadas a prática pedagógica do Licenciadola em Educação do Campo.

\section{Informações do Artigo / Article Information}

Recebido em : 30/08/2021

Aprovado em: 12/10/2021

Publicado em: 13/11/2021

Received on August 30th, 2021

Accepted on October 12th, 2021

Published on November, 13th, 2021

Contribuições no Artigo: Os(as) autores(as) foram os(as) responsáveis por todas as etapas e resultados da pesquisa, a saber: elaboração, análise e interpretação dos dados; escrita e revisão do conteúdo do manuscrito e; aprovação da versão final publicada.

Author Contributions: The author were responsible for the designing, delineating, analyzing and interpreting the data, production of the manuscript, critical revision of the content and approval of the final version published.

Conflitos de Interesse: Os(as) autores(as) declararam não haver nenhum conflito de interesse referente a este artigo.

Conflict of Interest: None reported.

Avaliação do artigo

Artigo avaliado por pares.

\section{Article Peer Review}

Double review.

Agência de Fomento

CNPq.

Funding 
CNPq.

\section{Como citar este artigo / How to cite this article}

APA

Silva, M. S., \& Alves, M. S. (2021). A contribuição da Licenciatura em Educação do Campo UFCG para a formação docente e a prática pedagógica das escolas no Cariri paraibano: concepção dos egressos. Rev. Bras. Educ. Camp., $\quad 6, \quad$ e12973. http://dx.doi.org/10.20873/uft.rbec.e12973

\section{ABNT}

SILVA, M. S.; ALVES, M. S. A contribuição da Licenciatura em Educação do Campo UFCG para a formação docente e a prática pedagógica das escolas no Cariri paraibano: concepção dos egressos. Rev. Bras. Educ. Camp., Tocantinópolis, v. 6, e12973, 2021. http://dx.doi.org/10.20873/uft.rbec.e12973 